\title{
Física solar: uma experiência de ensino remoto durante a pandemia
}

\author{
Solar physics: an experience in remote teaching during the pandemic \\ Física solar: uma experiencia em la enseñanza remota durante la pandemia
}

\author{
Bruno Fernandes Garcia \\ ORCID: https://orcid.org/0000-0002-6508-3746 \\ Universidade Federal de Alfenas, Brasil \\ E-mail: bruno.fernandes@sou.unifal-mg.edu.br \\ Samuel Bueno Soltau \\ ORCID: https://orcid.org/0000-0002-7211-2533 \\ Universidade Federal de Alfenas, Brasil \\ E-mail: samuel.soltau@unifal-mg.edu.br
}

\begin{abstract}
Resumo
O distanciamento e o isolamento social adotados como algumas das medidas de proteção da população durante a pandemia de COVID-19 impôs adaptações nas dinâmicas de ensino e de aprendizagem. Em resposta aos desafios surgidos, as instituições de ensino e, em especial os professores e alunos antes acostumados ao ensino presencial, viramse diante da alternativa do ensino remoto. Neste contexto, relata-se aqui uma experiência de ensino remoto ocorrida durante o primeiro ano da pandemia no qual se vislumbrou na impossibilidade da realização de aulas presenciais numa escola da zona rural de Minas Gerais, uma oportunidade de desenvolver e utilizar um material polivalente para ser utilizado no ensino remoto como também no ensino presencial. O material, criado com o intuito de promover a autonomia do estudante com o auxílio do professor, insere temáticas relacionadas com a Física Solar no âmbito dos tópicos de Física abordados no ensino básico. A experiência teve êxito em promover as atitudes esperadas dos alunos como se pode depreender dos relatos dos próprios estudantes que participaram das atividades de ensino.
\end{abstract}

Palavras-chave: Ensino de física; Física solar; Ensino remoto; Materiais didáticos; Relato de experiência.

\begin{abstract}
The distance and social isolation adopted as some of population protection measures during the COVID-19 pandemic imposed adaptations in the teaching and learning dynamics. In response to the challenges that arose, educational institutions and, in particular, teachers and students previously used to face-to-face teaching, envisaged the alternative of remote teaching. In this context, we report here a remote teaching experience that occurred during the first year of the pandemic, in which it was perceived that it was impossible to carry out face-to-face classes at a school in the rural area of Minas Gerais, an opportunity to develop and use multipurpose material to be used in remote as well as face-toface teaching. The material, created with the aim of promoting student autonomy with the help of the teacher, inserts themes related to solar physics within the scope of physics topics covered in basic education. The experience was successful in promoting the students' expected attitudes as can be seen from the reports of the students themselves who participated in the teaching activities.
\end{abstract}

Keywords: Physics teaching; Solar physics; Emergency remote teaching; Courseware; Experience report.

\section{Resumen}

La distancia y el aislamiento social adoptados como algunas de las medidas de protección de la población durante la pandemia COVID-19 impusieron adaptaciones en las dinámicas de enseñanza y aprendizaje. En respuesta a los desafíos que surgieron, las instituciones educativas y, en particular, los docentes y estudiantes anteriormente acostumbrados a la docencia presencial, enfrentaron la alternativa de la enseñanza remota. En este contexto, reportamos aquí una experiencia de enseñanza a distancia ocurrida durante el primer año de la pandemia, en la cual se percibió que era imposible realizar clases presenciales en una escuela de la zona rural de Minas Gerais, una oportunidad para desarrollar y utilizar material multiusos para ser usado tanto en la enseñanza remota como presencial. El material, creado con el objetivo de promover la autonomía de los estudiantes con la ayuda del profesor, inserta temas relacionados con la Física Solar dentro del ámbito de los temas de física cubiertos en la educación básica. La experiencia fui exitosa en promover las actitudes esperadas de los estudiantes como se puede ver en los informes de los propios estudiantes que participaron en las actividades docentes.

Palabras clave: Enseñanza de la física; Física solar; Enseñanza remota de emergencia; Material didáctico; Informe de experiencia. 


\section{Introdução}

Todos os mecanismos de vida e seres vivos da Terra dependem direta ou indiretamente da dinâmica e das reações nucleares presentes no Sol. Com o intuito de apresentar tais temas aos alunos do Ensino Médio, elaborou-se um material didático que aborda desde a transformação de energia solar nos processos que ocorrem na superfície do planeta Terra até a nucleossíntese dos elementos químicos pesados.

O propósito foi criar, desenvolver e utilizar um material didático flexível o bastante para ser utilizado tanto no contexto do isolamento social provocado pela pandemia de COVID-19, que deixou aos professores e alunos apenas a alternativa do ensino remoto, quanto a sua aplicação no âmbito da sala de aula do ensino presencial. A exigência de polivalência do material foi imposta pelos autores por entenderem que o esforço para se criar e desenvolver um material inovador, de qualidade, que aborda temas pouco difundidos no ensino básico conforme apontam Aroca (2009) e Aroca et al (2012) capaz de englobar um conjunto de conceitos físicos e possibilitar a discussão contextualizada, não deveria ter seu uso restrito apenas a um período de exceção como o do ensino remoto devido à pandemia.

Para atender as prescrições dos conteúdos dos documentos nacionais (Brasil, 2018) e regionais (Minas Gerais, 2018) regulatórios do ensino, o material produzido buscou desenvolver a reflexão crítica dos alunos em relação aos temas correlacionados e complementares à Física Solar, tais como: calor, temperatura, ondas e energia.

O uso do material na vigência do ensino remoto atribuiu papéis bem definidos tanto ao professor quanto aos alunos. Coube ao professor auxiliar, sanar dúvidas, analisar os principais tópicos do material junto aos estudantes e, posteriormente, discutir com eles suas respostas e comentários feitos sobre o conteúdo do material. Aos alunos, destinatários privilegiados e foco principal de toda a proposta, coube o papel de entender a proposta e proceder ao estudo do material da forma mais autônoma e dedicada possível.

As "pranchas", como foram denominados os materiais didáticos criados devido ao seu formato físico, são constituídas por textos curtos, ilustrações, menções das relações dos temas com o cotidiano dos alunos e diversos exemplos para facilitar a exposição do assunto com objetividade, clareza e descontração.

Nas atividades e exercícios propostos há histórias em quadrinhos, cuja propriedade de utilização no ensino de Física já foi evidenciada por Pena (2003), Silva (2005), Lacerda (2019) e Caruso et al (2021) entre outros. Assim como Vasconcelos (2018) e Olivares et al. (2017) também se utilizou palavras cruzadas no processo de ensino como ferramenta didática. Concordase com Olivares et al. (2017) que palavras cruzadas tendem a despertar habilidades no estudante que possibilitam o aperfeiçoamento de capacidades necessárias à autonomia e com Franklin et al. (2003) que elas são úteis para reforçar definições e conceitos teóricos.

O uso alternado destes e outros recursos tiveram a expectativa de remeter às atividades lúdicas e, deste modo, buscar suavizar as tarefas destinadas ao aluno durante a vigência do ensino remoto. Toda a estratégia de ensino aplicada nas pranchas pretendeu possibilitar ao estudante desenvolver um processo de aprendizagem autônomo e a apropriação dos conceitos físicos apresentados e discutidos. Assim como Seixas et al (2020, p.21), acreditamos que “[...] o uso e a aplicação de diferentes métodos de ensino articulados podem ser o caminho para romper com um ensino descontextualizado, sem significado para o aprendiz ou focado na repetição e memorização de fórmulas".

Houve, por parte dos autores, a intenção explícita de escapar dos formatos e suportes dos materiais didáticos convencionais na confecção das pranchas. Além disso, os textos das pranchas evitam os clichês de linguagem usualmente presentes nos livros-texto didáticos. Cada termo técnico ou científico é rigorosamente definido e explicado. A expectativa dos autores foi a de causar um "estranhamento" inicial no aluno ao se deparar com um material que difere dos estereótipos habituais e, com isso despertar a curiosidade e conduzi-lo a investigar o conteúdo envolvendo-o num processo que o desafia a aprofundar cada vez mais na temática abordada. 
Assim posto, o propósito deste artigo é relatar a experiência da aplicação das pranchas, apresentar em detalhe as características relevantes e distintivas do material elaborado e sua utilização com alunos durante o ensino remoto, apresentando indícios de que a proposta de possibilitar a autonomia no processo de aprendizagem e o enfoque na temática de Física Solar, no âmbito dos tópicos do segundo ano do Ensino Médio, foram alcançados.

\section{Metodologia}

Caracteriza-se este trabalho como um relato de experiência, de abordagem qualitativa uma vez que, prioriza mais a interpretação do pesquisador do fenômeno em estudo do que a mensuração dos dados (Denzin \& Lincoln, 2006; Pereira et al, 2018) e a análise das informações se dá por meio de um processo indutivo (Lüdke \& André, 2013) como, por exemplo, a análise qualitativa das críticas, comentários e respostas dos alunos voluntários apresentadas neste artigo.

A experiência relatada aqui envolve a construção e desenvolvimento de materiais didáticos e sua aplicação na forma de sequências didáticas com a temática de Física Solar abordando os tópicos de Física que podem ser correlacionados à esta temática e que constam do Conteúdo Básico Comum (CBC) de Física do Ensino Médio - Exames Supletivos (Minas Gerais, 2018), quais sejam, ondulatória, óptica e termodinâmica. Além destes temas aborda-se também as reações nucleares que ocorrem no Sol e as transformações de energia na superfície da Terra.

Neste artigo, uma sequência didática pode ser entendida como "um conjunto de atividades ordenadas, estruturadas e articuladas para a realização de certos objetivos educacionais, que têm um princípio e um fim conhecidos tanto pelo professor como pelos alunos" (Zabala, 1998, p. 18).

Em termos de organização, a primeira sequência didática aborda tópicos de ondulatória relacionando-os à temática de Física Solar. A segunda sequência apresenta e discute a produção de energia no Sol através das reações nucleares interiores, relacionando-as aos conteúdos de termodinâmica e outros relacionados com a transformação de energia.

A ideia inicial do projeto visava a construção e desenvolvimento de sequências didáticas e, posteriormente, sua aplicação em salas de aula presenciais. Com o advento da pandemia de COVID-19 e a necessidade de isolamento social, os autores decidiram não apenas adaptar, mas reinventar o projeto criando soluções e materiais completamente novos e com as características próprias para atender tanto ao ensino remoto quanto ao ensino presencial.

A estratégia de uso do material foi planejada para atender às demandas de aprendizagem de alunos durante o ensino remoto que dispunham de internet precária ou mesmo inexistente e também aos alunos que revelaram ter dificuldades de estudar pelos materiais que foram disponibilizados a eles pelos órgãos oficiais de ensino. Portanto, o material ofereceu suporte à aprendizagem dos alunos no período de estudo domiciliar que foi instituído durante a pandemia, com a expectativa que cada estudante assumisse o protagonismo de sua aprendizagem, tornando-se um aprendiz autônomo, responsável em grande parte por seu processo de aprendizagem recorrendo ao professor somente quando julgasse necessário.

O uso das pranchas foi apoiado, quando necessário e possível, através dos aplicativos de comunicação tais como Whatsapp e Google Meet, com grupos de alunos do segundo ano do Ensino Médio da Escola Estadual Judith Vianna, do município de Alfenas, MG e da Escola Estadual Clóvis Salgado, localizada na zona rural do município de São Sebastião do Paraíso, MG.

Ao propor a aplicação e o uso do material, foi avisado explicitamente aos alunos que não se tratava de atividade obrigatória, conforme estabelece as normativas vigentes no Estado de Minas Gerais na Resolução SEE No 4310/2020 (Minas Gerais, 2020).

Deste modo, os alunos participantes foram perfeitamente esclarecidos de que a participação era voluntária. Também foi necessário o envolvimento das direções e equipes pedagógicas das escolas participantes no sentido de divulgar a iniciativa e solicitar a adesão, engajamento e participação dos alunos voluntários à proposta. Assim as pranchas serviram como material 
complementar de ensino nos estudos remotos.

O status de material complementar de conteúdos da Física facilitou sua inserção na rotina de estudos dos alunos e agregou liberdade aos autores para transitar entre os conteúdos estudados no bimestre vigente e outros previamente estudados em períodos letivos anteriores. Essa situação favoreceu a instauração de uma perspectiva mais ampla acerca dos conteúdos abordados com os participantes e contribuiu para uma integração mais abrangente dos temas e propiciou a oportunidade de romper com a visão fragmentária de conteúdos que costuma prevalecer por vezes no ensino com material convencional.

Entretanto, como não era uma atividade obrigatória, houve uma adesão à proposta que pode ser considerada reduzida quando comparada com o número de estudantes nas escolas em condições presenciais ordinárias. Porém, a participação precisa ser colocada em contexto, não apenas em função da situação de exceção instaurada pela pandemia, como também ter em vista que nem todos alunos são receptivos às inovações didáticas, alguns preferindo refugiar-se em práticas ortodoxas e familiares e da constatação assistemática de que nem todos alunos se adaptaram bem ao ensino remoto, preferindo o ensino presencial por fatores variados que fogem ao escopo deste relato discutir.

O procedimento adotado foi o envio das pranchas aos alunos participantes via aplicativos de comunicação estipulando o prazo de uma semana para a sua utilização, o que incluía a leitura dos textos e resolução das atividades e exercícios.

Como os participantes já vinham estudando de forma remota e utilizando o material fornecido pela Secretária Estadual de Educação criado especificamente para o ensino durante o período do isolamento social, cujo conteúdo se superpunha parcialmente aos das pranchas, a estratégia de ensino proposta foi integrada sem dificuldades adicionais às rotinas de estudo e trabalho dos participantes.

Ao longo de uma semana, os estudantes que se disponibilizaram a estudar o material, discutiram e tiravam dúvidas com o professor, via aplicativos de comunicação, realizando tanto as leituras dos textos como a resolução dos exercícios propostos.

Para exemplificar o tipo de interação que ocorreu durante o uso das pranchas com os alunos voluntários das escolas rurais, apresentamos a seguir um diálogo via aplicativo de comunicação feito por um aluno do segundo ano (Figura 1) e um comentário a respeito da qualidade das pranchas feito por uma aluna do mesmo ano (Figura 2).

Na Figura 1, após estudar o conteúdo das pranchas que abordam o tema de ondulatória, um aluno do $2^{\circ}$ ano procura o professor para conferir seus raciocínios durante os cálculos efetuados para um dos exercícios propostos, a fim de certificar-se de que entendeu o procedimento dos cálculos envolvendo frequência. Este tipo de diálogo foi recorrente entre os participantes e o professor.

Figura 1: Questionamento de um participante durante o uso da prancha que trata de ondulatória: "Agora eu divido 1 por 480? Ou tem q fazer mais coisas"

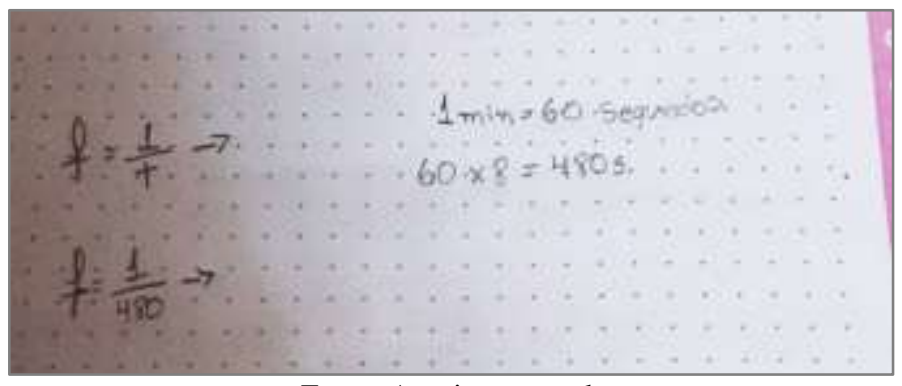

Fonte: Arquivo pessoal.

Ao término de cada uma das sessões de estudo, que ocorriam dentro do prazo estipulado, mas no momento escolhido pelos alunos, foi solicitado aos participantes que enviassem fotos das resoluções dos exercícios, bem como quaisquer críticas a respeito das pranchas em parte ou no todo, falassem a respeito do nível de dificuldade que tiveram na resolução dos exercícios 
e das atividades, a clareza e objetividade dos textos, diagramas e gráficos incluídos nas pranchas ou quaisquer outros comentários que considerassem relevantes.

O trecho de texto mostrado na Figura 2 é um exemplo típico do tipo de feedback recebido dos participantes. Neste caso o texto veio de uma aluna do segundo ano do Ensino Médio. No texto do seu comentário a aluna ressalta o que, na sua percepção, deveria ser aprimorado na prancha que aborda a temática do calor e destaca o aspecto lúdico escolhido para o formato das atividades.

Figura 2: Opinião de uma aluna do segundo ano do ensino médio participante quanto ao material.

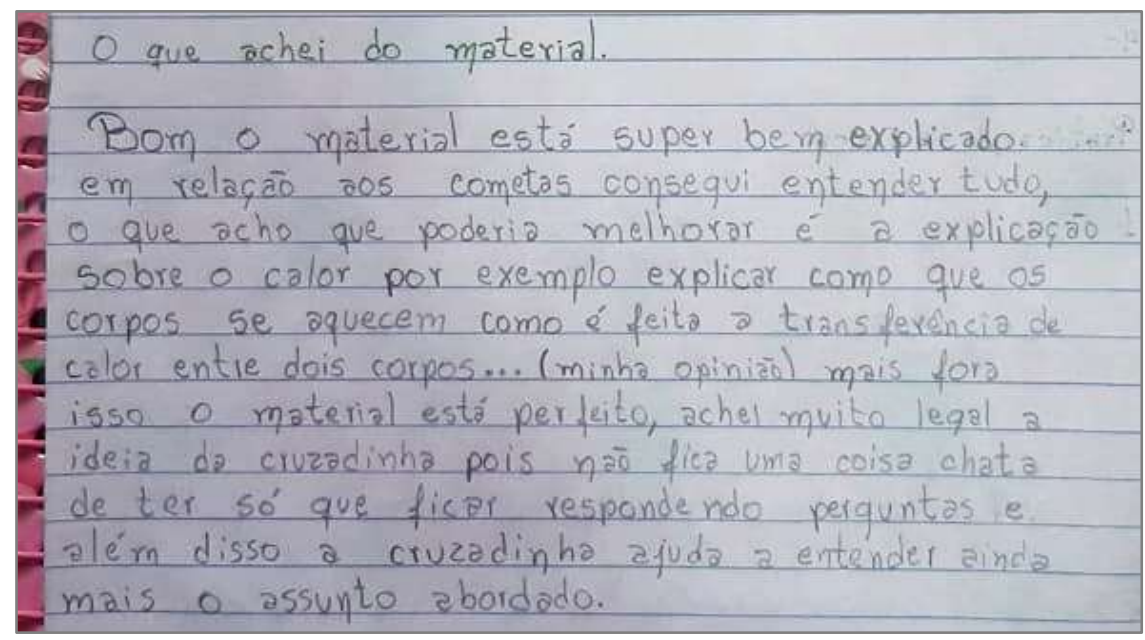

Fonte: Autores.

O conteúdo das interações mereceu uma análise detida e criteriosa por parte dos autores, a fim de aprimorar a criação e o projeto das pranchas seguintes, bem como a metodologia de utilização e a aplicabilidade junto aos alunos durante o ensino remoto. Além disso, considerando que as pranchas foram pensadas para uso polivalente, ou seja, também no ensino presencial ordinário, os comentários e a avaliação dos participantes foram fundamentais na deteç̧ão de aspectos e fatores que poderiam dificultar a aplicação futura da metodologia no ensino presencial.

A seguir, apresentamos como as pranchas foram planejadas e desenvolvidas, suas características de formato e conteúdo e, na sequência, a proposta que permeia sua aplicação e discussões gerais.

\subsection{O Material}

De maneira a não se tornar mais uma atividade entediante ou, na visão dos estudantes, mais um "trabalho" ou "dever de casa", muito menos evocar a referência de materiais similares às apostilas oficiais distribuídas pela Secretaria de Educação durante a pandemia de COVID-19, bem como se distanciar na aparência dos livros didáticos que os alunos já conhecem e manipulam desde que ingressam na escola, após muita discussão e pesquisa os autores decidiram adotar o formato de "lâminas" com conteúdos autocontidos, mas que se vinculam, umas às outras não apenas por extensão física do suporte - em papel - no qual foi impressa, mas também pelo aprofundamento da temática desenvolvida em cada kit ou conjunto de materiais. Por fim, a denominação de "pranchas" acabou prevalecendo como a mais adequada para designar o material.

Ao longo das pranchas, há pequenos desenhos nos vértices das folhas - os ícones - de maneira que o aluno precisa interligá-las e montar a sequência numa espécie de quebra-cabeça para continuar e aprofundar o estudo da temática coberta em cada conjunto de pranchas. A necessidade de montar um quebra-cabeça, por mais simples que seja o mero ato de comparar os ícones nos vértices das pranchas para compor a sequência de estudo, permite uma pausa recreativa do ato de estudar ao mesmo tempo que desvincula a tarefa de aprender da noção de uma atividade realizada enquanto se manipula um caderno, apostila, livro, 
ou mesmo se "navega" na internet.

As pranchas são materiais "off line", em suporte papel, mas que guardam elementos de materiais de em suporte digital, tais como a diagramação, cuidado com o número de palavras, o formato e a linguagem empregada nos textos, tipo de figuras, diagramas e gráficos etc., mas que não remetem a algo parecido com material didático convencional e ortodoxo usualmente encontrado nas escolas. Essa "surpresa" ou "estranheza" diante do inusitado das pranchas é um dos elementos que os autores esperavam provocar nos alunos a fim de associar ludicidade e curiosidade à autonomia do ato de aprender e "estudar em casa", sejam nas "lições de casa" do ensino presencial, sejam nas atividades do ensino remoto durante a pandemia.

As pranchas são fartamente ilustradas. Textos curtos e objetivos exploram analogias e exemplos evocando situações cotidianas. Os "exercícios" e "problemas" possuem um formato que visa intencionalmente associar ludicidade e a habilidade de explorar o repertório aprendido pelo aluno, tais como: cruzadinhas, história em quadrinhos, entre outros.

A presença de jogos tem caráter complementar aos conceitos mais abstratos discutidos nas pranchas e foram inseridos num local específico do material que visa provocar uma pausa na concentração do estudante, antes de retomar o estudo do conteúdo e, deste modo, estimular o aluno a continuar o estudo da prancha. A formatação das páginas alterna entre "paisagem" e "retrato", conforme a necessidade de encaixar melhor os elementos do conteúdo da prancha e romper com a monotonia da página impressa do livro-texto ou apostila convencional.

A diagramação de todas as pranchas foi realizada no software gratuito LibreOffice Writer. As imagens utilizadas são de autoria própria ou de domínio público. Portanto, os direitos autorais de todo conjunto de pranchas independem de copyright e pode ser utilizado livremente. E, embora o desenvolvimento das pranchas tenha sido norteado pelos documentos oficiais do estado de Minas Gerais, como o currículo de ensino da Física varia relativamente pouco ao longo dos estados brasileiros é esperado que possa ser utilizado em escolas, professores e estudantes de todo o Brasil.

Na Figura 3, apresenta uma das pranchas que integra o conjunto que trata da temática calor, utilizada com os alunos do segundo ano do Ensino Médio das duas escolas de que trata este relato de experiência.

Figura 3: Prancha temática a respeito de calor.

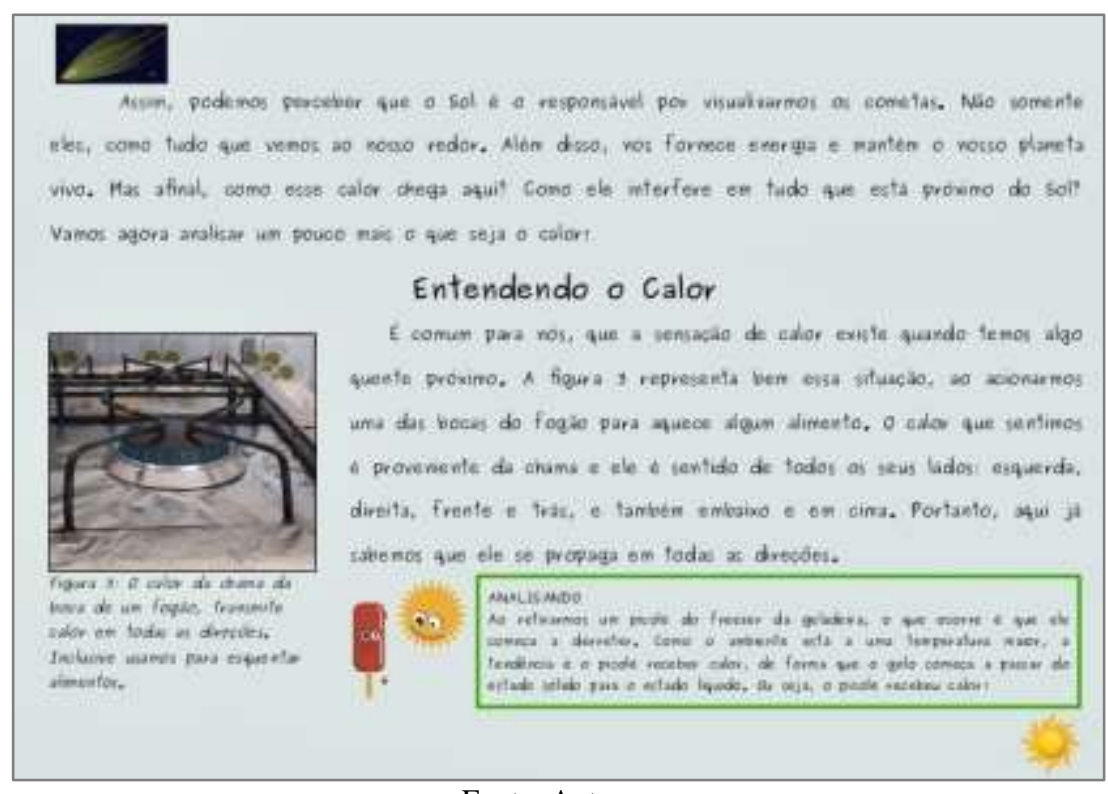

Fonte: Autores.

No que se refere às características da disposição dos conteúdos na prancha mostrada na Figura 3, os textos, não ultrapassam 5 ou 6 linhas. Pequenas caixas de texto dispostas ao longo da área da prancha, destacam informações complementares ou mencionam "curiosidades" relacionadas aos tópicos em estudo, a fim de romper com a linearidade da 
narrativa didática e produzir uma dinâmica e um ritmo de apresentação do conteúdo que busca construir uma interação dialógica com o aluno.

O intuito de todos estes artifícios narrativos, textuais e visuais é suscitar a curiosidade do aluno para temas correlatos e ser um elemento motivador a mais para o estudante, que, de modo autônomo, elabora uma conexão entre seus conhecimentos prévios e os novos apresentados nas pranchas. Além disso, a temática de Física Solar permite isso, conforme mencionado por Ribeiro et al (2019).

Como apresentado na Figura 4, o uso de equações segue encadeado ao texto, no qual cada termo ou variável é apresentado acompanhado do seu significado físico, de maneira que o aluno perceba cada expressão como um refraseamento mais objetivo do conceito físico estudado. A construção e discussão gradual, expondo cada etapa da escrita matemática das equações, visa fornece a base conceitual necessária para que o estudante possa acompanhar o raciocínio envolvido.

Figura 4: Prancha temática a respeito de ondulatória.

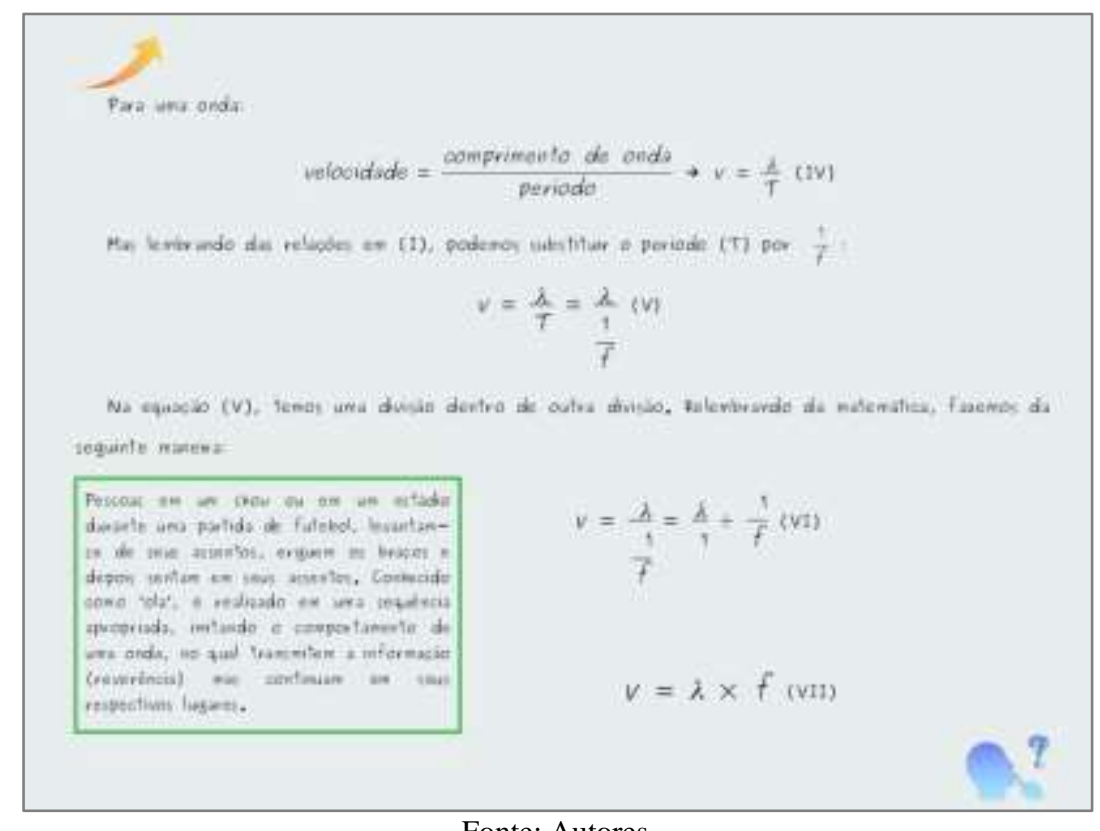

Fonte: Autores.

Há problemas propostos relativos aos temas apresentados e discutidos ao longo de todas as pranchas. Cada problema segue a mesma dinâmica das caixas de texto: romper a apresentação didática linear convencional. Alternando conteúdo, caixas de texto, problemas, quizes etc., entremeados de texto curtos em linguagem objetiva, torna-se um ritmo leve, lúdico e consistente com a proposta didática subjacente à ideia das pranchas.

Nas Figuras 5 e 6, mostramos exemplos dos tipos de jogos e de história em quadrinhos que fazem parte da prancha. Ressaltamos que, tanto os jogos quanto as histórias em quadrinhos, reforçam algum aspecto da temática abordada na prancha e os conceitos discutidos, não são adicionados de forma aleatória, apenas para suavizar o tempo de estudo ou mudar o foco do estudante. Apenas o ritmo narrativo é quebrado, não o ritmo de estudo. 
Figura 5: Exemplos dos jogos didáticos e história em quadrinho.

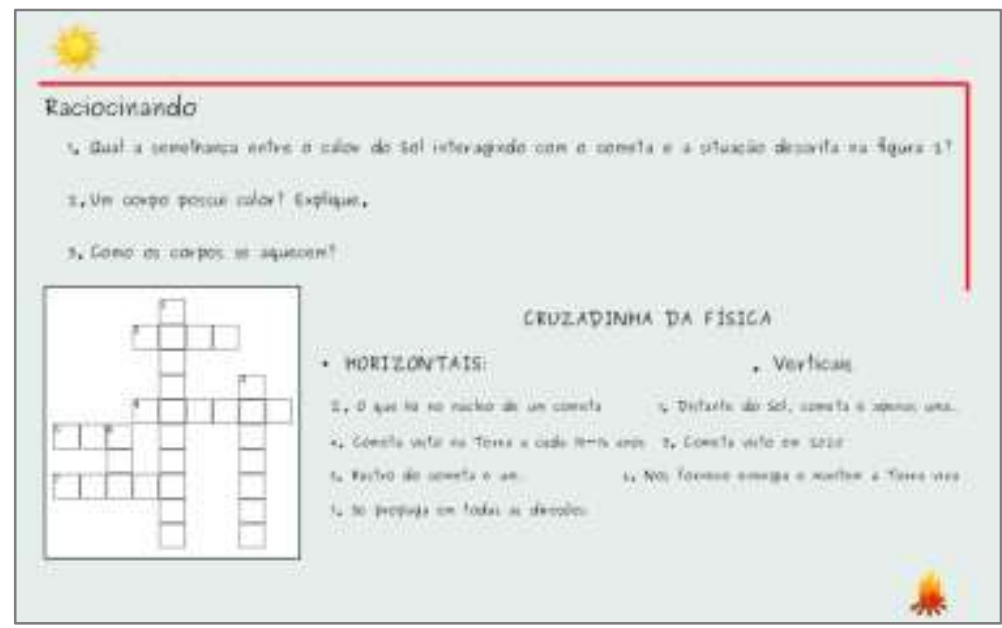

Fonte: Autores.

Figura 6: Exemplo de história em quadrinho e cruzadinha.

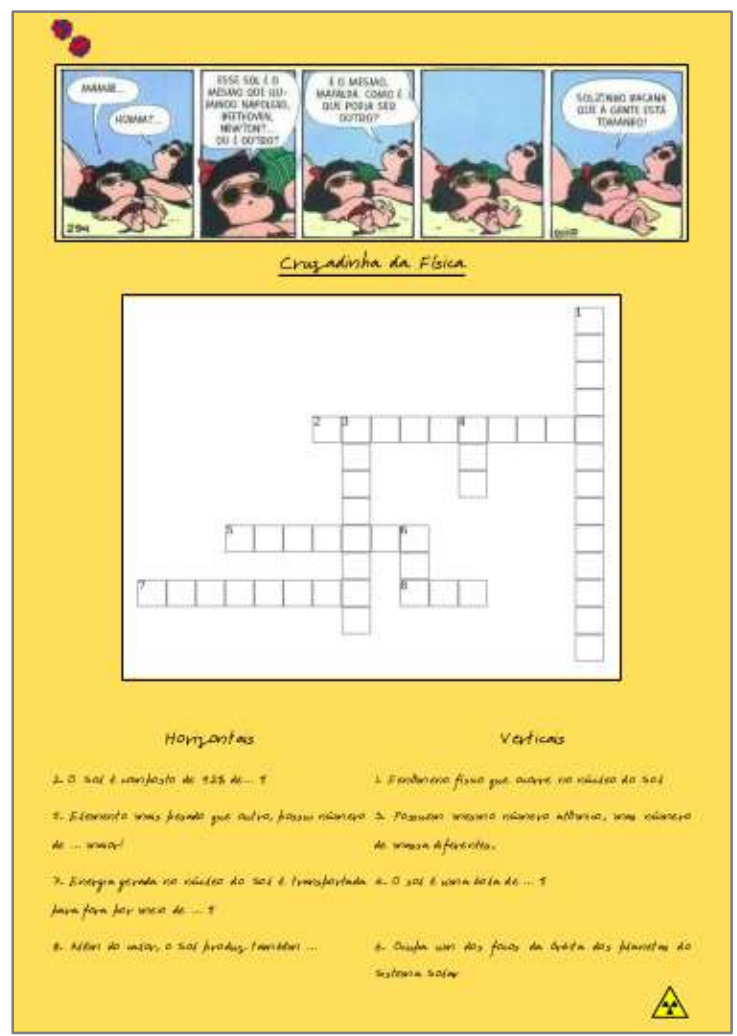

Fonte: Autores.

Apresentamos e discutimos as impressões obtidas dos participantes durante o uso das pranchas.

\section{Resultados e Discussão}

O contexto no qual a experiência relatada ocorreu foi o de meados do terceiro bimestre do ano de 2020, em plena pandemia. Os estudantes voluntários receberam as pranchas e a proposta começou a ser colocada em prática junto aos alunos no momento em que o material didático produzido pela Secretaria de Estadual de Educação era distribuído. Essa coincidência ofereceu a possibilidade de contrastar o uso de um material desenvolvido nos moldes tradicionais e a proposta didática das pranchas. 
Em certos casos houve coincidência inclusive entre as temáticas tratadas no material oficial da Secretaria Estadual de Educação e os tratados nas pranchas. Este foi o caso do estudo de ondulatória e da introdução ao estudo do calor. O aspecto mais evidente é que, enquanto no material oficial não houve qualquer preocupação de estabelecer vínculos entre os temas de calor e ondulatória, nas pranchas o vínculo não só era explícito como também os abordou de maneira que os estudantes puderam compreender que são temas correlatos e que o domínio de sua aplicação se estende para aspectos cotidianos.

Dada a extensão do material recolhido, apresentaremos e discutiremos mais profundamente aqui apenas os relatos do uso da prancha da temática de ondulatória, intitulada “Cometa Neowise”, bem como os comentários, críticas feitas pelos estudantes participantes da experiência e suas dúvidas referentes às atividades do material. Ressaltamos que todos estes apontamentos serviram para aperfeiçoar as pranchas seguintes. Houve a participação de 11 estudantes, de ambas as escolas.

As atividades que exigiam a habilidade de escrita foram entregues sem questionamento adicional por parte de qualquer participante. As atividades estruturadas na forma de palavras cruzadas, mostradas na Figura 2, foram as que mais surpreenderam os alunos, tendo sido alvo de comentários elogiosos por parte deles. Quando questionados a respeito dessa preferência, os alunos disseram gostar muito das "cruzadinhas" pois traziam "uma ideia de jogar e ao mesmo tempo de aprender sobre a matéria".

Praticamente todas as dúvidas e dificuldades relatadas pelos participantes, recaíram nas atividades que envolviam cálculos. Um exemplo do tipo de dúvida recorrente dos estudantes está em destaque na Figura 7 e também pode ser observado na Figura 1. Nos demais tipos de exercícios, não houve dúvida explícita na forma de recurso à ajuda docente.

Figura 7: "Professor, eu tava respondendo às questões. Daí chegou nas de contas deu um bug no cérebro kkkk... Não Tô sabendo qual conta exatamente usar"

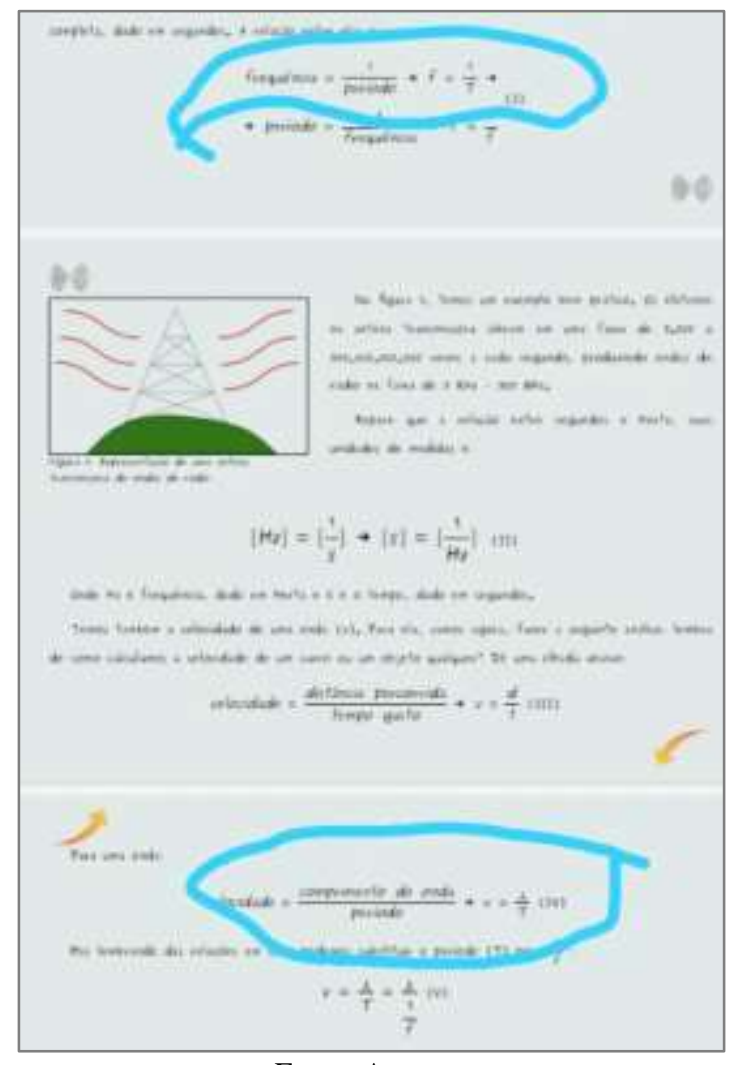

Fonte: Autores.

Houve ainda comentários a respeito da ajuda que a numeração das equações trouxe à compreensão no entendimento das expressões matemáticas. Estes comentários chamaram especial atenção porque numerar equações é um recurso habitual e corriqueiro em textos de artigos científicos e livros técnicos. 
Entretanto, apesar das pranchas apresentarem o desenvolvimento gradual, passo a passo das expressões e relacioná-las aos conceitos de forma clara e objetiva, os alunos ainda apresentaram dificuldades em aplicá-las na resolução dos exercícios. As justificativas mais frequentes apresentadas pelos próprios participantes foram:

- Não ter conhecimento de quando deveriam aplicar as "fórmulas" no exercício;

- Dificuldade na manipulação de variáveis da equação;

- Dificuldades com o método de mudança de unidades de tempo.

Ao final de cada temática os participantes enviavam seus comentários e críticas a respeito das pranchas e, ao término da experiência, as contribuições foram analisadas e selecionadas as que indicavam a possibilidade ou a necessidade de aprimoramento da proposta.

Neste contexto de dúvidas relacionadas à manipulação de equações algébricas, por exemplo, um estudante sugeriu que as pranchas trouxessem exemplos de exercícios resolvidos mostrando como trabalhar com as equações em cada temática. Em suas palavras:

“... A explicação das fórmulas estão mto top, e achei interessante q vc numerou as fórmulas e isso facilitou muuitooo. Na minha opinião, seria legal se tivesse um exercício como exemplo, resolvido usando uma das fórmulas. Demorei pra entender um pouquinho como funciona na hora d fazer as contas e tals, por isso. Mas estão bem fáceis os últimos exercícios e ajuda a entender bastante o conteúdo. Não tenho críticas pq ficou muito bom."

Com relação às dificuldades dos participantes no desenvolvimento de cálculos e na manipulação algébrica, ponderamos que devemos ser cautelosos ao atribuir esta dificuldade ao modo como as equações foram apresentadas nas pranchas, uma vez que é notória a dificuldade histórica que os alunos têm em matemática, conforme apontam, entre outros, De Lima et al (2020) e Leite, de Bonamino (2020). Observamos, ainda que de modo assistemático, que os participantes da experiência com as pranchas não estavam familiarizados com a abordagem de deduzir as equações passo a passo. Além disso, na construção desse raciocínio, usar letras ao invés de números, não é algo comum para eles. Tanto que quando se trata de cálculos envolvendo apenas números a mesma dificuldade não emerge. Na mudança de unidades, essa dificuldade foi analisada também por Menezes (2019).

Porém, apesar dessas dificuldades relatadas, após breve discussão com o professor via aplicativos de comunicação, os participantes conseguiram encaminhar satisfatoriamente a resolução dos problemas nos exercícios subsequentes nos quais há a presença de cálculos. Por exemplo, na seção "Raciocinando", eles não apresentaram dificuldade ou solicitaram qualquer tipo de auxílio para resolvê-los. Provavelmente, após revisar o material com a ajuda do professor, entenderam a construção e o desenvolvimento das equações, e, é claro, sua aplicação.

Os comentários positivos, após relativizados, tendo em perspectiva o impacto inicial provocado pelo formato inusitado das pranchas, foram reservados para uma análise mais detida tendo em vista seu uso para aprimorar o material já elaborado e instruir a confecção dos seguintes.

\section{Conclusão}

Neste relato de experiência, procuramos evidenciar a possibilidade de criar, desenvolver e usar um material didático alternativo e flexível o suficiente para favorecer a aprendizagem, tanto no ensino presencial convencional quanto no ensino remoto. Ressaltamos que não se tratou aqui de "adaptar" ou "reorganizar" materiais preexistentes usados no ensino presencial de forma a que pudessem ser utilizados durante o isolamento social provocado pela pandemia de COVID-19, mas sim, de criar um conjunto de materiais com potencial para uso tanto no ensino presencial quanto no ensino remoto.

Através dos comentários obtidos e da interação com os participantes analisadas ao longo deste relato, incluindo as intervenções através dos aplicativos de comunicação, é possível argumentar que o conjunto de pranchas atendeu as expectativas 
para as quais foram projetadas, haja vista a reação exibida pelos estudantes participantes. Embora tenham ocorrido dificuldades relativas à manipulação de equações algébricas durante a aplicação e uso das pranchas, tais dificuldades não podem ser atribuídas de maneira inequívoca ao formato ou à estratégia de apresentação didática dos conteúdos das pranchas uma vez que as dificuldades dos alunos com a matemática são frequentemente relatadas e notadamente conhecidas.

As temáticas escolhidas, podem ser consideradas uma "prova de conceito" para uma estratégia de ensino pensada, para tentar obter a participação, o engajamento e favorecer a autonomia e o protagonismo dos alunos no processo de aprendizagem, características necessárias para qualquer proposta de ensino, sobretudo quando se trata de ensino remoto.

A ideia de abordar tópicos de Física Solar, mostrou-se proveitosa e foi bem recebida pelos estudantes, conforme se percebe nos depoimentos recolhidos. A proposta de aliar conteúdos obrigatórios segundo as normas e portarias da Secretaria de Educação, com temáticas que geralmente não são contempladas nos currículos, mas que têm importância central na compreensão do mundo, mostrou-se profícua e por certo merecerá ser ampliada e aprofundada nas próximas pranchas a serem confeccionadas. Portanto, considerando os resultados obtidos em relação à proposta pretende-se, em trabalhos futuros, estender e expandir as pranchas para abordar novos temas no ensino da Física.

Finalmente, teremos que aguardar o retorno à normalidade das atividades escolares a fim de submeter as pranchas a teste durante o ensino presencial ordinário, sem as pressões impostas pelo isolamento social e a pandemia. Entretanto, como as pranchas foram pensadas para serem utilizadas pelos estudantes em suas residências, visando oferecer uma possibilidade e oportunidade a mais de aprendizagem além de quaisquer outras circunstancialmente vigentes, esta experiência - ou prova de conceito - contém elementos e características até mais rigorosas do que o ensino presencial para avaliar o sucesso na aplicação do material. Uma vez que mesmo nas condições menos favoráveis da pandemia, as pranchas tiveram boa aceitação por parte dos estudantes, não há razão para acreditar que seriam rechaçadas em circunstâncias mais favoráveis.

\section{Referências}

Aroca, S. C. (2009). Ensino de física solar em um espaço não formal de educação. 173 f. Tese (Doutorado em Ciências) - Instituto de Física de São Carlos, Universidade de São Paulo. 10.11606/T.76.2009.tde-13032009-100501.

Aroca, S. C., Colombo Jr., P. D., \& Silva, C. C. (2012). Tópicos de Física Solar no Ensino Médio: análise de um curso com atividades práticas no observatório Dietrich Schiel. Revista Latino-Americana de Educação em Astronomia, (14), 7-25. doi.org/10.37156/RELEA/2012.14.007

Brasil. (2018). Ministério da Educação; Secretaria de Educação Básica. Base Nacional Comum Curricular (BNCC). MEC/ SEB

Caruso, F., Daou, L., Marques, A. \& Silveira, F. (2021). Tirinhas de Física: propostas para a sala de aula. Livraria da Física.

De Lima, P. V. P., Moreira, G. E., Vieira, L. B., \& Ortigão, M. I. R. (2020). Brasil no Pisa (2003-2018): reflexões no campo da Matemática. TANGRAM-Revista de Educação Matemática, 3(2), 03-26.

Denzin, N. K. \& Lincoln, Y. (2006). Planejamento da pesquisa qualitativa: teorias e abordagens. (2a ed.), ARTMED.

Franklin, S.; Peat, M. \& Lewis, A. (2003). Non-traditional interventions to stimulate discussion: the use of games and puzzles. Journal of Biological Education, 37(2), 79-84. doi.org/10.1080/00219266.2003.9655856

Leite, A. F. M., \& de Bonamino, A. M. C. (2020). Defasagem idade-série e letramento científico no Pisa. Estudos em Avaliação Educacional, 31(77), 393-420. doi.org/10.18222/eae.v31i77.7103

Lüdke, M. \& André, M. E. D. A. (2013) Pesquisa em educação: abordagens qualitativas. EPU.

Menezes, K. B. de L. (2019). Física solar: ensinando tópicos de Física Moderna para o Ensino Médio. 85f Trabalho de Conclusão de Curso (Graduação em Física) - Instituto de Física, Universidade Federal Fluminense.

Minas Gerais (2020). Secretaria de Estado de Educação. Resolução SEE N4.310/2020. Governo do estado de Minas Gerais. https://www2.educacao.mg.gov.br/images/documentos/4310-20-r\%20-\%20Public.\%2018-04-20.pdf.

Minas Gerais. (2018). Secretaria de Estado da Educação de Minas Gerais [SECMG]. Conteúdo Básico Comum (CBC) - Física / Ensino Médio. Belo Horizonte.

Olivares, J., Escalante, M., Escarela, R., Campero, E., Hernández, J., \& López, I. (2017). Los crucigramas en el aprendizaje del electromagnetismo. Revista Eureka Sobre Enseñanza Y Divulgación De Las Ciencias, 5(3), 334-346. https://revistas.uca.es/index.php/eureka/article/view/3744 
Research, Society and Development, v. 10, n. 3, e49910313495, 2021

(CC BY 4.0) | ISSN 2525-3409 | DOI: htttp://dx.doi.org/10.33448/rsd-v10i3.13495

Lacerda, P. C. de C. (2019). O lúdico no ensino de Física: eletrostática via quadrinhos. 2019. 120 f. Dissertação (Mestrado Profissional em Ensino de Ciências) - Instituto de Ciências Exatas e Biológicas, Universidade Federal de Ouro Preto, Ouro Preto.

Pena, F. L. A. (2003). Como trabalhar com "tirinhas" nas aulas de Física. Física na Escola, 4(2), 20-21.

Pereira A. S., Shitsuka D. M., Parreira F. J., \& Shitsuka R. (2018). Metodologia da pesquisa científica. UFSM. https://repositorio.ufsm.br/bitstream/handle/1/ 15824/Lic_Computacao_MetodologiaPesquisa-Cientifica.pdf?sequence=1/.

Ribeiro, A.S., Moreira, M. D., Ovigli, D. F. B., Oliveira, A. R., \& Colombo Junior, P. D. (2019). Prácticas innovadoras en la enseñanza de física moderna en una escuela pública brasileña. Revista de estudios y experiencias en educación, 18(36), 241-256. doi.org/10.21703/rexe.20191836ribeiro2.

Seixas, G. dos S., Santarosa, M. C. P., \& Ferrão, N. S. (2020). Educação Financeira na EJA: proposta de uma sequência didática à luz da Teoria da Aprendizagem Significativa Crítica. Research, Society and Development, 9(11), e3739119803. https://doi.org/10.33448/rsd-v9i11.9803

Silva, C. L. da (2005). Uma proposta de ensino de Física a distância usando tirinhas. Monografia de Conclusão de Curso, Universidade do Estado do Rio de Janeiro, Rio de Janeiro, RJ, Brasil.

Vasconcelos, T. T. (2018). O uso da astronomia com auxílio de tecnologias e dinâmicas para o ensino da física. 2018. 140 f. Dissertação (Mestrado Nacional Profissional em Ensino de Física) - Pró-Reitoria de Pesquisa e Pós-Graduação, Universidade Federal do Ceará, Fortaleza.

Zabala, A. (1998). A prática Educativa: como ensinar. Artmed. 